\title{
Game Edukasi Pengenalan Negara Negara ASEAN Untuk Siswa SMP Kelas VIII Berbasis Android
}

\section{Educational Game Introducing ASEAN Countries For Android Class VIII Middle School Students}

\author{
Jihan Nadila ${ }^{1}$, Irfan Santiko $^{2}$, Retno Waluyo ${ }^{3}$ \\ 1,2 Fakultas Ilmu Komputer, Program Studi Informatika, Universitas Amikom Purwokerto \\ ${ }^{3}$ Fakultas Ilmu Komputer, Program Studi Sistem Informasi, Universitas Amikom Purwokerto \\ e-mail: jihannadila99@gmail.com ${ }^{1}$, irfan.santiko@amikompurwokerto.ac.id ${ }^{2}$, \\ waluyo@amikompurwokerto.ac.id ${ }^{3}$
}

\begin{abstract}
Abstrak
Pekembangan teknologi saat ini semakin pesat. pemanfaatan game atau permainan sangat menunjang siswa dalam proses belajar dikelas. Pada saat materi mengenal negara-negara di ASEAN siswa akan lebih cenderung bosan karena pengenalan peta negara, ibu kota dan kenampakan alam hanya terdapat dibuku saja perlu adanya media pembelajara yang harus digunakan oleh guru agar siswa tidak cepat bosan dalam pembelajaran. Tujuan dari penelitian ini adalah agar mempermudah guru dalam penyampaian materi dan mempermudah siswa dalam mempelajari materi pengenalan negara-negara ASEAN. Game edukasi ini dikembangkan menggunakan metode MDLC (Multimedia Development Life Cycle) Oleh karena itu, dibuatlah suatu game edukasi pengenalan negara-negara di ASEAN yang sesuai dengan kurikulum 2013. Dari hasil suvei kepada 30 responden, didapatkan nilai rata - rata 92,19\% sehingga masuk kedalam kategori Sangat Setuju terhadap Game "Edukasi Pengenalan Negara Negara ASEAN untuk Siswa SMP Kelas VIII Berbasis Android" untuk diterapkan sebagai media belajar alternative.
\end{abstract}

Kata Kunci: Android, Game Edukasi, MDLC, Negara ASEAN

\begin{abstract}
Technological developments are booming. Game or game use is particularly helpful in the learning process. At a time when materials are familiar with the countries of asean students will be more likely to get bored because the state map introduction, the capital and naturalness are only in the books, the need for a learning medium to be used by teachers so that students do not get bored quickly. The purpose of research is to make teachers easier in delivery of materials and easier students to study asean's introduction materials. The educational game was developed using multimedia development life cycle, as the result of the MDLC method (multimedia development life cycle), a introduction to countries in the asean program that matches the 2013 curriculum. The survey of 30 respondents scored an average of $92.19 \%$, thereby falls into a category strongly in favor of the "educational introduction to asean state for siosswa middle school vii for android based" to be adopted as an alternative medium.
\end{abstract}

Keywords: Android, Educational Game, MDLC, ASEAN Countries

\section{Pendahuluan}

Perkembangan teknologi saat ini semakin pesat terutama dalam bidang game [1]. Dalam era globalisasi, teknologi informasi melaju dengan cepatnya untuk mendapatkan informasi yang lengkap mengenai sebuah negara, tidaklah cukup dengan hanya membaca buku saja [2]. Teknologi pendidikan adalah suatu teknologi yang mendukung kegiatan pendidikan sebagai alat bantu meningkatkan proses belajar siswa dan pengaplikasian teknologi pendidikan membuat kegiatan belajar menjadi luas lebih dari sekedar interaksi dengan guru dan murid di dalam ruang dan waktu yang terbatas [3]. Hal ini disebabkan informasi yang disajikan buku pelajaran masih tergolong minim. Aplikasi pengenalan Negara ASEAN ditujukan untuk siswa-siswi sekolah dasar dalam mempelajari dan mengenal Negara Anggota ASEAN, dimana siswa-siswi dapat lebih mudah mempelajarinya dibanding dengan hanya membacanya melalui buku saja yang kadang isinyapun kurang menarik dan juga untuk menambah pengetahuan mereka [4].

Salah satu teknologi pembelajaran adalah membuat sebuah game edukasi yang dapat membantu siswa untuk memahami materi tentang negara-negara di ASEAN. Game edukasi tersebut akan diterapkan untuk siswa SMP kelas VIII guna membantu siswa dalam memahami materi tersebut [5]. Dalam game 
edukasi ini siswa bukan hanya belajar tetapi akan merasa terhibur. Pembuatan game edukasi ini bertujuan untuk bisa membantu proses belajar IPS. Game edukasi ini akan diimplementasikan di SMP Raden Fatah Cimanggu untuk pelajaran IPS (Ilmu Pengetahuan Sosial). SMP Raden Fatah Cimanggu ini memiliki masalah dalam memahami perbedaan Negara - Negara ASEAN khususnya untuk kelas VIII [6]. Game edukasi merupakan sebuah game yang dapat membantu siswa - siswi agar belajar semakin mudah dipahami [7].

Penelitian terdahulu yang dilakukan oleh [8] dengan menggunakan metode MDLC (Multimedia Development Life Cycle) untuk mengembangkan aplikasi sehingga dapat digunakan dengan baik sebagai media pembelajaran [9] siswa - siswi untuk mempelajari materi IPS tentang Geografi. Menggunakan game edukasi ini sangat efektif dalam belajar siswa - siswi. Dari penjelasan diatas maka peneliti ini akan membuat game edukasi sebagai media pembelajaran Ilmu Pengetahuan Sosial dengan menggunakan metode pengembangan multimedia MDLC (Multimedia Development Life Cycle) untuk membantu siswasiswi memahami materi Geografi.

\section{Metode Penelitian}

Pada penelitian ini menggunakan metode MDLC untuk pengembangan multimedia. Metode MDLC memiliki enam tahapan yaitu consept, desing, material collecting, assembly, testing, dan distributif, berikut tahapan-tahapan pengembangan multimedia [10] :

\section{A. Concept}

Pembuatan game edukasi ini merupakan game yang bertujuan sebagai media pembelajaran. Game ini ditujukan untuk siswa SMP kelas VIII dalam memahami perbedaan Negara di ASEAN [10]. Game pembelajaran tersebut di sesuaikan dengan buku IPS kelas VIII yang ada di SMP Raden Fatah Cimanggu dan tentnya dibuat untuk membantu guru dalam menyampaikan materi Geografi tentang Negara ASEAN serta untuk menarik siswa dan siswi agar paham dengan materi yang disampaikan. Game ini dijalankan oleh satu orang pemain saja, didalam game tersebut ada sebuah pertanyaan yang membahas tentang materi Negara di ASEAN hanya dilakukan untuk satu orang pemain agar bisa melanjutan ke sesi pertanyaan berikutnya.

B. Design

Berikut deskripsi dari setiap scene yang menggambarkan perancangan aplikasi game edukasi matematika bilangan dan faktor prima [10].

\section{Storyboard}

Storyboard dibuat berdasarkan perancangan konsep sebelumnya. Tujuan dari storyboard yaitu untuk memberikan gambaran atau ilustrasi visual yang berurutan tentang aplikasi yang akan dibuat.
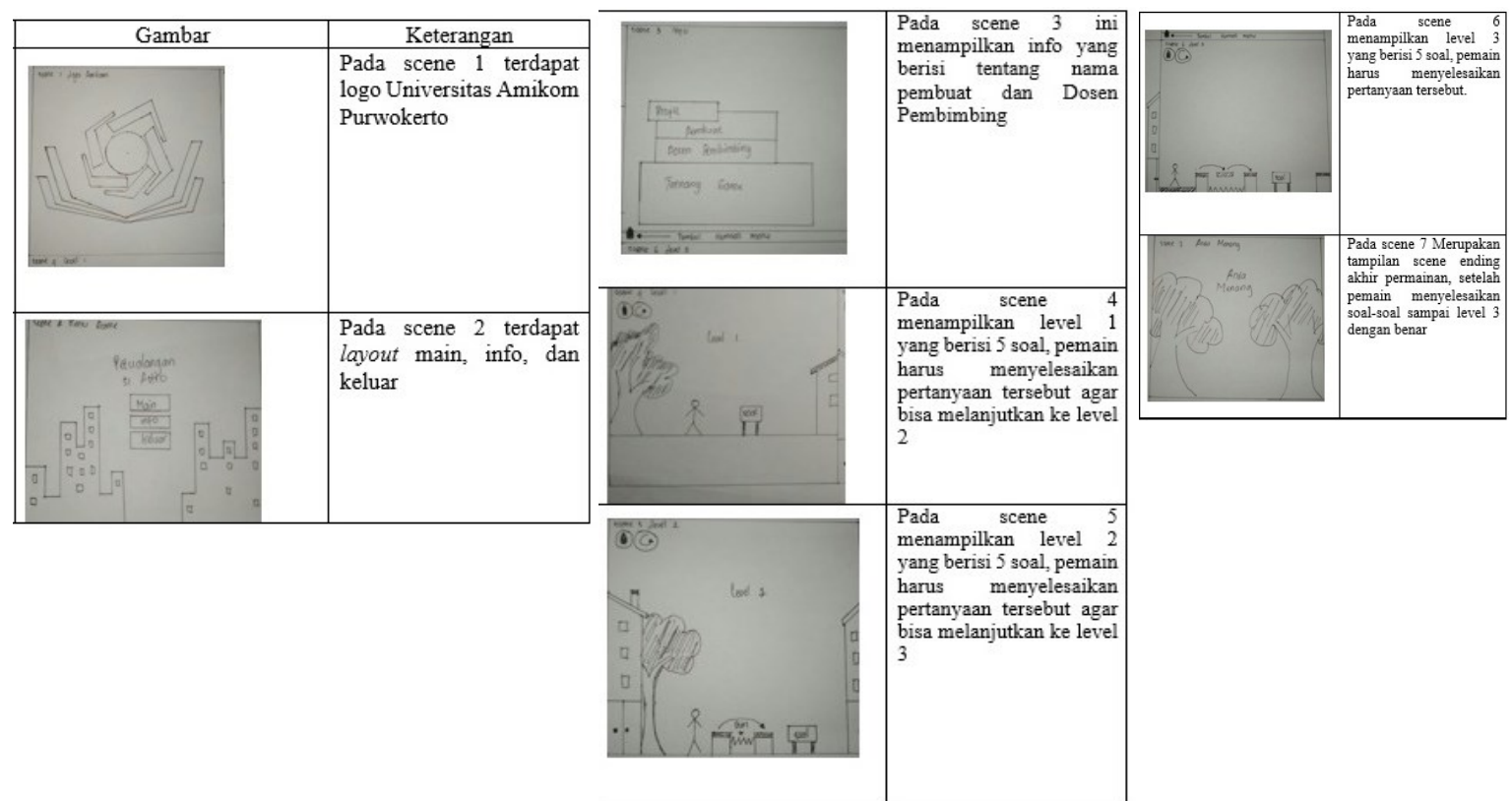

Gambar 1. Storyboard

JINITA Vol. 3, No. 1, June 2021 


\section{Struktur Navigasi}

Alur informasi dari suaru aplikasi untuk menggambarkan dengan jelas hubungan dal alur kerja seluruh elemen yang digunakan dalam aplikasi. Dengan penggambaran struktur navigasi aplikasi dapat sistematis dan mudah. Rancangan navigasi pada game edukasi ini untuk siswa kelas VIII B SMP Raden Fatah Cimanggu menggunakan Unity, meliputi:

\section{Material Collecting}

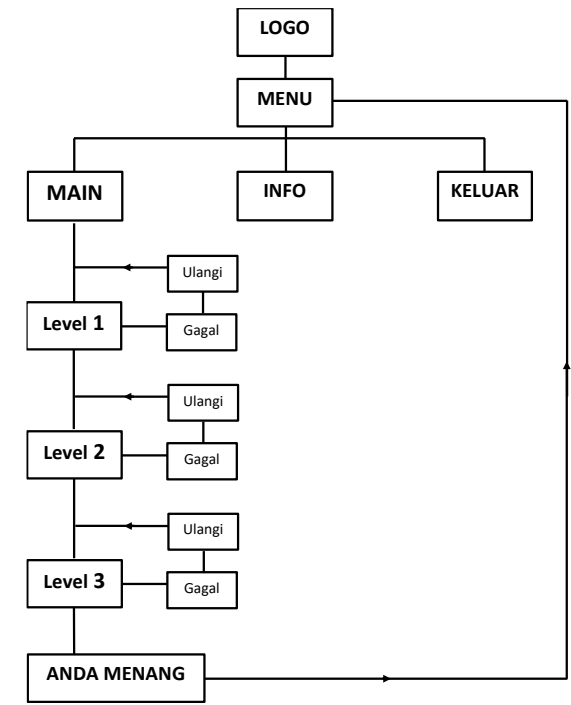

Gambar 2. Struktur Navigasi

Merupakan tahap pengumpulan bahan. Bahan yang dikumpulkan untuk pembuatan game ini adalah gambar, suara, teks, dan gambar sebagai bahan pendukung.

\section{Assembly}

Tahap assembly adalah tahap pembuatan objek multimedia berdasarkan perancangan yang telah dibuat sebelumnya. Dalam tahap ini penulis menggunakan Adobe Photoshop CS5 sebagai media pembuatan asset-asset game, dan Unity3d sebagai pembuatan program game.

\section{Hasil dan Pembahasan}

Proses pembuatan dari game edukasi segabai media pembelajaran materi Geographic sub Pengenalan Negara - Negara di ASEAN :

a. Pembuatan asset-asset game pada Adobe Photoshop CS5

1. Pembuatan karakter anak sekolah Pembuatan komponen dalam game

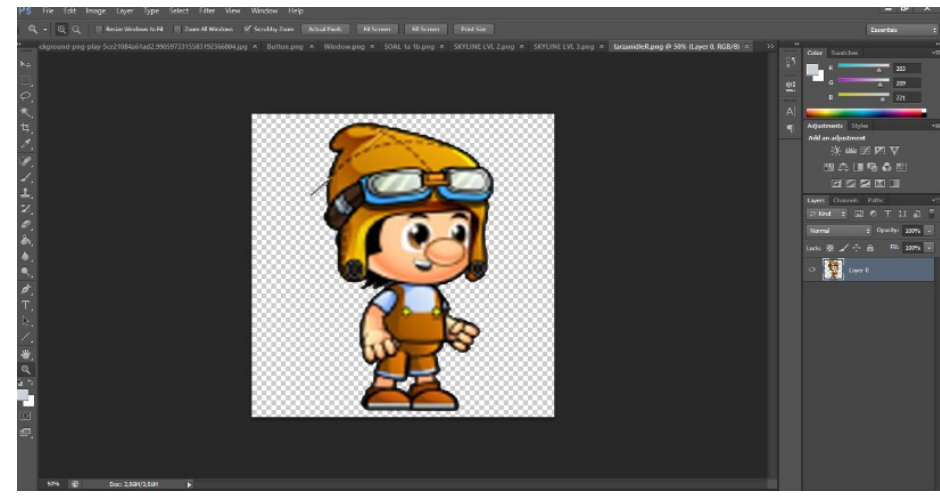

Gambar 3. Pembuatan Karakter

2. Pembuatan komponen dalam game

Tahap ini merupakan proses pembuatan komponen dari game yang meliputi judul, tombol, dan komponen lainya dalam game yang menggunakan adobe photoshop 


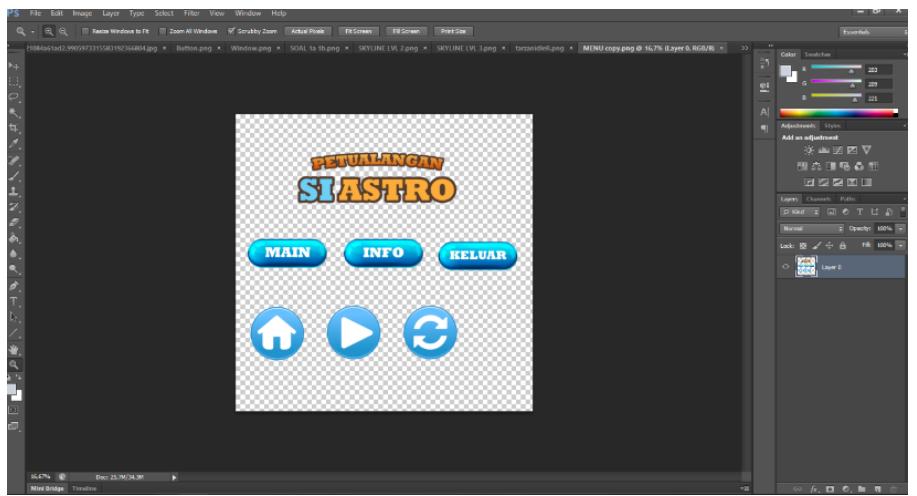

Gambar 4. Pembuatan bahan judul dan tombol

b. Pembuatan game edukasi

1. Opening game Edukasi

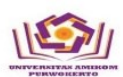

Gambar 5. Logo Amikom

Pada gambar 5 adalah opening game edukasi yang akan dimainkan dengan logo dari Universitas Amikom Purwokerto.

2. Menu Utama

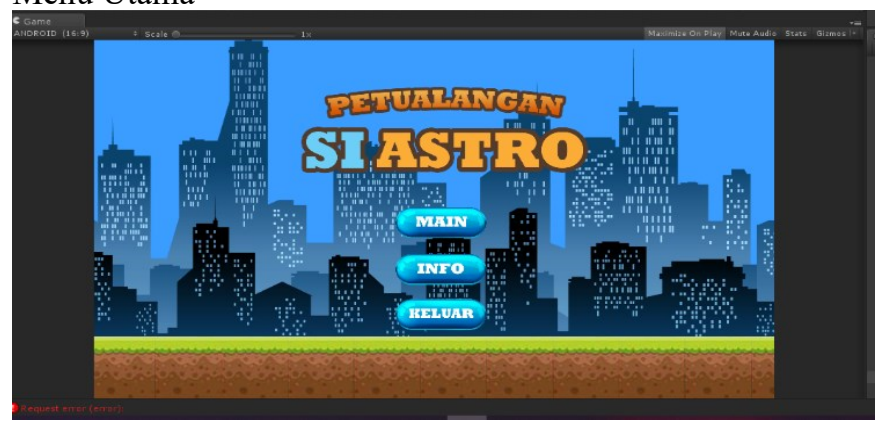

Gambar 6. Menu Utama

Pada gambar 6 diatas adalah tampilan dari menu utama game Petualangan Si Astro terdiri dari menu main, info, dan keluar.

3. Info Pembuatan

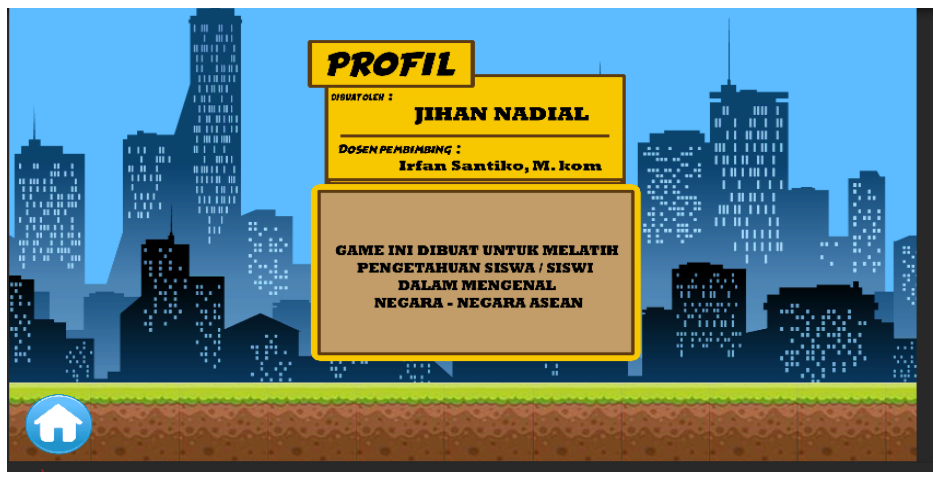

Gambar 7. Info Pembuatan 
Pada Gambar 7 Info Pembuat berisi tentang info dari pembuat game petualangan Si Astro yakni nama pembuat game dan dosen pembimbing skripsi.

4. Tampilan Level 1

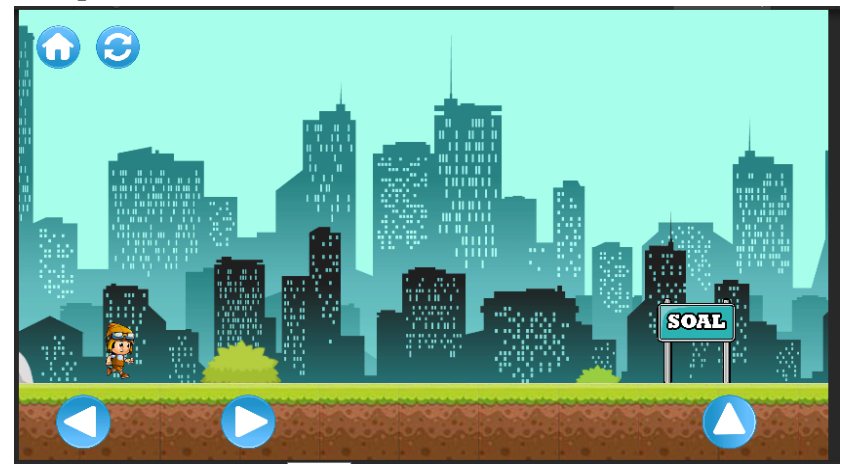

Gambar 8. Tampilan Level 1

Pada gambar 8 Tampilan Level adalah tampilan gambar dari level 1 terdapat karakter. Dalam level 1 harus melewati soal dan rintangan. Dalam level ini terdapat 5 tombol yaitu tombol arah kiri untuk mundur, tombol kanan untuk maju, tombol ke atas untuk loncat, tombol kembali untuk kembali ke menu, dan tombol restart untuk ulangi permainan.

5. Tampilan Level 2

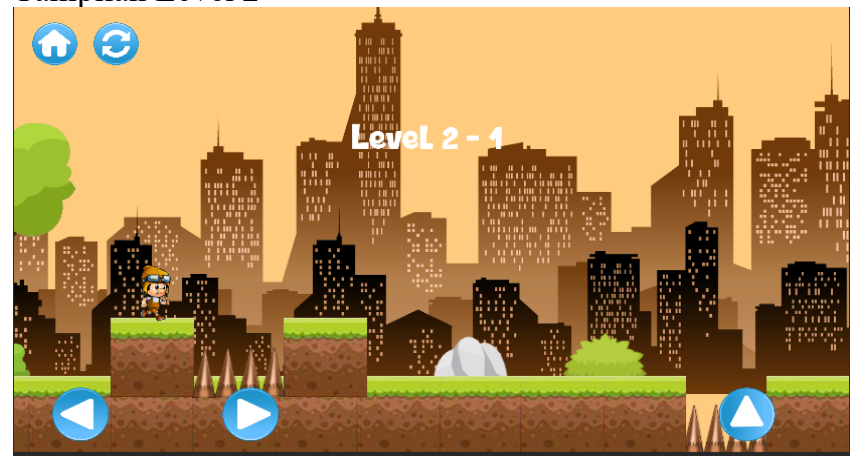

Gambar 9. Tampilan Level 2

Pada gambar 9 adalah tampilan gambar dari level 2 terdapat karakter. Dalam level 2 harus melewati rintangan berduri dan papan. Dalam level ini terdapat 5 tombol yaitu tombol arah kiri untuk mundur, tombol kanan untuk maju, tombol ke atas untuk loncat, tombol kembali untuk kembali ke menu, dan tombol restart untuk ulangi permainan.

6. Tampilan Level 3

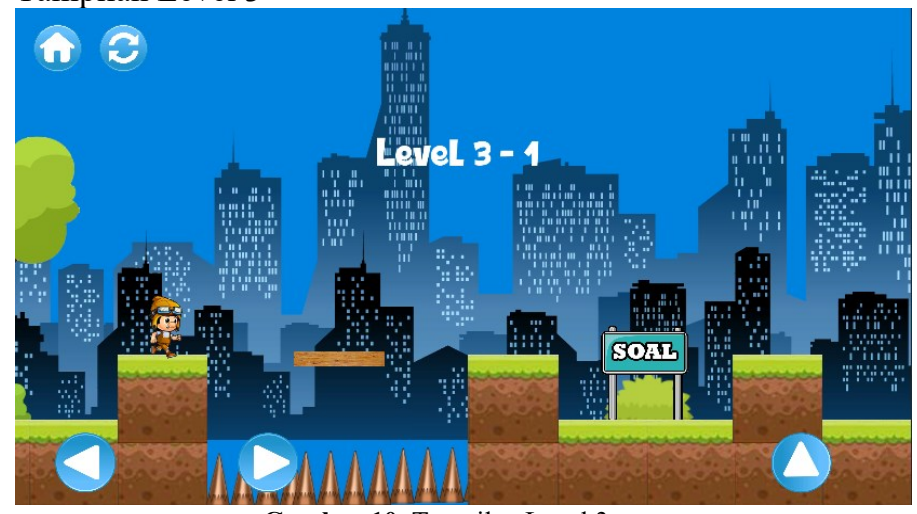

Gambar 10. Tampilan Level 3 
Pada gambar 10 adalah tampilan gambar dari level 3 terdapat karakter. Dalam level 3 harus melewati rintangan berduri dan papan. Dalam level ini terdapat 5 tombol yaitu tombol arah kiri untuk mundur, tombol kanan untuk maju, tombol ke atas untuk loncat, tombol kembali untuk kembali ke menu, dan tombol restart untuk ulangi permainan.

7. Tampilan Soal

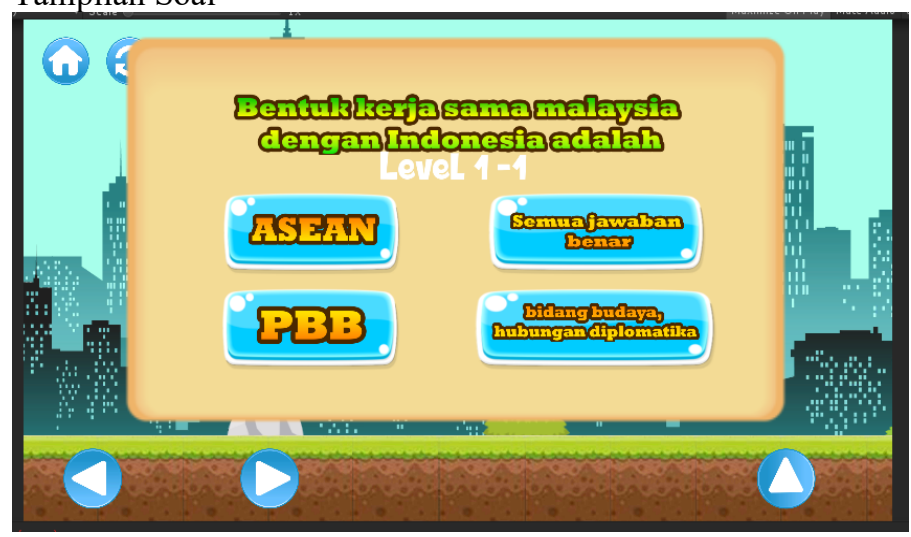

Gambar 11. Tampilan Soal

Pada gambar 11 adalah tampilan dari soal, tampilan ini akan munculsetelah karakter sudah melewati semua rintangan

8. Tampilan Anda Menang

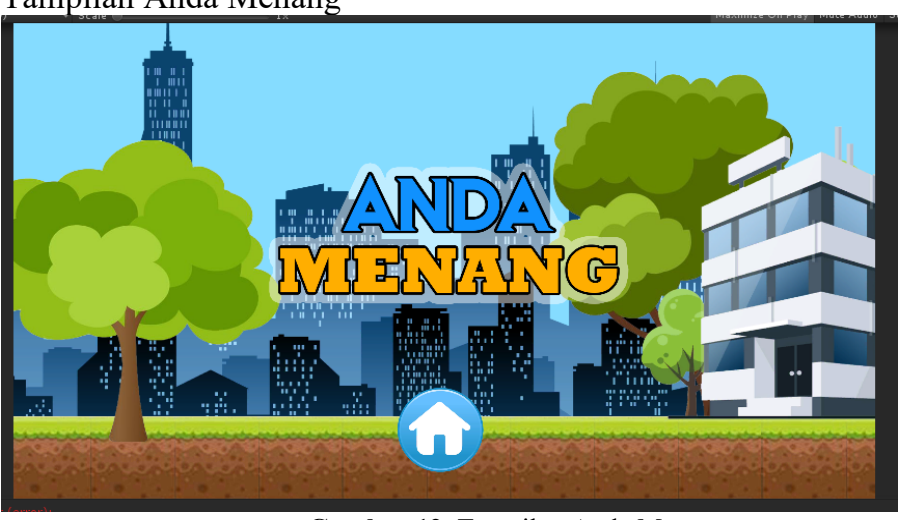

Gambar 12. Tampilan Anda Menang

Pada gambar 12 diatas merupakan tampilan anda menang setelah pemain sudah menyelesaikan semua permainan dengan benar menjawab soal dari level 1-3 lalu akan muncul tampilan anda menang.

\section{E. Testing}

Dalam tahap ini dilakukan pengetesan menggunakan metode alpha Test dan Beta Test merupakan metode yang dilakukan oleh pembuat atau lingkungan pembuatannya sendiri. Setelah lolos dari Alpha Test. Maka akan dilakukan pengujian yang melibatkan pengguna akhir yaitu Beta Test.

\section{F. Distribution}

Pada tahap ini peneliti melakukan pendistributian aplikasi. Tahap ini dimulai dengan menyimpan aplikasi dalam perangkat smartphone android dalam bentuk format .apk. dan dapat menggunakan kabel data sebagai media transfer data melalui PC atau Laptop ke smartphone android dan juga bisa melalui Bluetooth kemudian di instal pada smartphone android. 
Berikut hasil kuesioner dengan responden siswa - siswi kelas VIII SMP Raden Fatah Cimanggu yang menyatakan kelayakan untuk game ini sebagai media pembelajaran materi Geografi sub Negara Negara ASEAN.

Tabel 1. Hasil Keusioner

\begin{tabular}{c|c|c|c|c|c}
\hline \multirow{2}{*}{ Pertanyaan } & \multicolumn{4}{|c|}{ Jumlah Penelitian } & \multirow{2}{*}{ Jumlah Responden } \\
\cline { 2 - 5 } & SS & S & KS & TS & 30 \\
\hline \multirow{2}{*}{1} & 28 & 2 & 0 & 0 & 30 \\
2 & 23 & 6 & 1 & 0 & 30 \\
3 & 15 & 14 & 0 & 1 & 30 \\
4 & 18 & 11 & 0 & 1 & 30 \\
\hline
\end{tabular}

Sangat Setuju (SS) $\quad: 4$

Setuju (S) : : 3

Kurang Setuju (KS) $\quad: 2$

Tidak Setuju (TS) $\quad: 1$

Tabel 2. Hasil Akhir Pengujian

\begin{tabular}{c|c|c}
\hline Pertanyaan & Indeks & Kategori \\
\hline 1 & $98,4 \%$ & Sangat Setuju \\
2 & $93,4 \%$ & Sangat Setuju \\
3 & $85,83 \%$ & Sangat Setuju \\
4 & $88,33 \%$ & Sangat Setuju \\
5 & $95 \%$ & Sangat Setuju \\
\hline
\end{tabular}

Rumus perhitungan skala Likert dari hasil kuesioner dapat menghasilkan sebagai berikut :

Dengan hasil rata-rata rumus index sebagai berikut :

$(98,4 \%+93,4 \%+85,83 \%+88,33 \%+95 \%) / 50=92,19 \%$

Jadi nilai rata - rata index dari responden sebesar 92,19\%, sehigga termasuk sangat setuju.

Dari hasil perhitungan kuesioner yang dilakukan peneliti, didapatkan nilai persentase 92,19\% yang merupakan nilai dalam kriteria sangat baik. Sehingga dari hasil berikut dapat diambil kesimpulan bahwa game edukasi pengenalan negara negara di ASEAN sebagai media pembelajaran sudah dapat membantu siswa - siswi SMP Raden fatah Cimanggu dalam memahami perbedaan yang ada di Indonesia dengan negara lain.

\section{Kesimpulan}

Setelah membuat game edukasi ini dapat disimpulkan bahwa peneliti ini telah berhasil membuat aplikasi ini sebagai media pembelajaran untuk materi Geografi ( sub Negara- Negara Asean ) pada perangkat berbasis android yang mencakup semua materi tersebut. Hasil dari pengujian dari kuesioner terdapat 30 responden dari kelas VIII SMP Raden Fatah Cimanggu dan didapatkan presentase 92,19\% yang tergolong dalam kategori sangat setuju sehingga game ini sudah layak diterapkan sebagai media pembelajaran materi Geografi ( sub Negara- Negara Asean ) di SMP Raden Fatah Cimanggu.

beberapa saran untuk pengembanggan dari peneliti selanjutnya agar penelitian ini kedepannya lebih baik, yaitu menambah objek area permainan, penambahan objek 3D, menambahkan lambang lambang disetiap negara. 


\section{Daftar Pustaka}

[1] R. Adiwakarta and H. B. Dirgantara. "Pengembangan Permainan Video Endless Running Berbasis Android Menggunakan Framework Game Development Life Cycle". Jurnal Sains dan Teknologi, Vol. 4 No.2, pp. 142-148, 2017.

[2] I.Binanto.. Multimedia Digital Dasar Teori dan Pengembangannya. Yogyakarta: ANDI OFFSET. 2010

[3] Dony Novaliendry. "Aplikasi Game Geografi Berbasis Multimedia Interaktif”. Jurnal Teknologi Informasi \& Pendidikan, Vol. 6 No. 2, pp. 106-118, 2013.

[4] Enok Maryani and Helius Syamsudin. "Pengembangan Program Pembelajaran IPS untuk Meningkatkan Kompetensi Keterampilan Sosial". Jurnal Penelitian. Vol. 9. No. 1, pp. 1-15, 2009.

[5] M. Firdaus. "Rancang Bangun Game Edukasi Asah Otak Anak Berbasis Android Menggunakan Aplikasi Construct 2". Jurnal Konvergensi Teknologi Informasi dan Komunikasi. Vol 12 No 1, pp. 1-10, 2016

[6] Moh Ahsan, Ta'Jillah Ibnu Fridyatma, "Rancang Bangun Game Edukasi Go Green "Mr.trashman" Menggunakan Adobe Flash." Bimasakti, 2014.

[7] Munir. Multimedia Konsep \& Aplikasi dalam Pendidikan. Bandung: Alfabeta, 2015

[8] Suindarti, Game Edukasi Meningkatkan Daya Ingat Anak "Bermain Bersama Dido" Dengan Macromedia Director, Jurusan Sistem Informasi, Sekolah Tinggi Manajemen Informatika Dan Komputer, Yogyakarta, 2011

[9] Dian Wahyu Putra, A. Prasita Nugroho, Erri Wahyu Puspitarini. "Game Edukasi Berbasis Android Sebagai Media Pembelajaran Untuk Anak Usia Dini”. Jurnal Informatika Merdeka Pasuruan,Vol.1 No.1, pp. 46-58, 2016.

[10] Mursid Yunus, Indah Fitri Astuti, Dyna Marisa Khairina. "Game Edukasi Matematika Untuk Sekolah Dasar”. Jurnal Ilmiah Ilmu Komputer. Vol. 10 No. 2, pp. 59-64, 2015 